\title{
MÉTODOS ATUAIS DE INVESTIGAÇÃO DO METABOLISMO PROTÉICO: ASPECTOS BÁSICOS E ESTUDOS EXPERIMENTAIS E CLÍNICOS
}

\author{
PROTEIN METABOLISM INVESTIGATION: CLINICAL AND EXPERIMENTAL ASPECTS
}

Júlio Sérgio Marchini', Júlio C. Moriguti², Gilberto J. Padovan³, Carla B. Nonino³, Silviane Maria Luna Vianna ${ }^{4}$, José Eduardo Dutra de Oliveira ${ }^{1}$

\begin{abstract}
${ }^{1}$ Docentes da Divisão de Nutrição Clínica do Departamento de Clínica Médica. ${ }^{2}$ Médico Assistente da Divisão de Clínica Médica Geral e Geriatria. ${ }^{3}$ Químico. ${ }^{4}$ Nutricionista. Hospital das Clínicas da Faculdade de Medicina de Ribeirão Preto - USP.

CorRESPONDÊNCIA: Divisão de Nutrição Clínica da Faculdade de Medicina de Ribeirão Preto - 14049-900 - Ribeirão Preto, SP, Brasil. Telefone: (016) 6330436 - Fax: (016) 6336695 - E-mail: jsmarchi@fmrp.usp.br
\end{abstract}

MARCHINI JS et al. Métodos atuais de investigação do metabolismo protéico: aspectos básicos e estudos experimentais e clínicos. Medicina, Ribeirão Preto, 31: 22-30, jan./mar. 1998.

RESUMO: Os métodos de investigação do metabolismo protéico no homem, de uso clínico, incluem desde a avaliação da proteína ingerida até a determinação específica da capacidade de síntese protéica total. Na presente revisão, são discutidos aspectos práticos relacionados ao: teor protéico, digestibilidade e composição, em aminoácidos, de alimentos; excreção urinária de produtos nitrogenados; balanço nitrogenado; nível de aminoácidos plasmáticos; níveis de substâncias específicas, relacionadas ao metabolismo protéico, incluindo técnicas de biologia molecular; e, por fim, determinação da taxa corpórea de síntese protéica. O método a ser utilizado e/ou recomendado vai variar de acordo com as necessidades e objetivos específicos de cada situação clínica. A avaliação da ingestão protéica, sua correlação com o estado geral do paciente, bem como a forma de oferta, resultam em melhora da qualidade geral do atendimento médico, bem como beneficiam a própria recuperação do paciente.

UNITERMOS: Proteínas. Nutrição. Metabolismo. Aminoácidos.

\section{INTRODUÇÃO}

O estudo do metabolismo protéico, visando aplicação clínica, abrange aspectos que vão desde a qualidade da proteína ingerida até o estudo com marcadores biológicos, para determinar a síntese protéica ${ }^{(1)}$. Deve-se, também, considerar que o metabolismo protéico sofre alterações relacionadas à quantidade ingerida de proteína. Assim, os vários aspectos do metabolismo protéico são diferentes em uma pessoa que ingere quantidade adequada de proteína tanto em aspectos quantitativos, quanto qualitativos e naquelas pessoas que a ingerem em excesso ou não a ingerem, e/ou o fazem numa relação inadequada de proteína/caloria ${ }^{(2)}$. A resposta metabólica protéica, em pessoa previamente bem alimentada, é diferente na pessoa mal nutrida e que sofre uma agressão orgânica, como o advento de uma doença ${ }^{(1,3)}$. A avaliação do estado nutricional protéico do paciente envolve aspectos relacionados à ingestão protéica, dados clínicos, antropométricos, laboratoriais e/ou metabólicos ${ }^{(4,5)}$. A avaliação da alimentação ingerida é feita por meio de inquéritos alimentares ou pela medida direta da proteína ingerida. Essa avaliação permite a verificação 
da adequação da dieta ingerida, bem como estimar, pela evolução do paciente, as suas maiores ou menores necessidade de nutrientes específicos. $\mathrm{O}$ exame clínico antropométrico pode sugerir alterações do conteúdo protéico, corpóreo/muscular, por meio da avaliação conjunta de peso, altura, circunferência muscular, média, do braço, bem como a evolução da morbidade geral do paciente. Os exames bioquímicos, por meio de determinação da proteína plasmática, enzima hepática e cálculo da taxa de reciclagem protéica, permitem estimar a taxa de síntese protéica. Os níveis urinários de uréia, nitrogênio, creatinina, hidroxiprolina e $\mathrm{n}^{\mathrm{t}}$-metilistidina avaliam a degradação protéica.

De uma maneira resumida ${ }^{(1,2,6)}$, os principais sistemas bioquímicos, envolvidos na manutenção da homeostase protéica e aminoacídica, no organismo, são: 1) a captação e transporte de aminoácidos; 2) oxidação e catabolismo dos aminoácidos; 3) síntese protéica e 4) degradação protéica. Aparentemente, a primeira resposta do organismo a uma menor ingestão protéica e/ou de aminoácidos essenciais é uma redução acentuada da massa protéica corpórea, mesmo em processos carenciais agudos (Figura 1), acompanhada de redução da taxa de oxidação de aminoácidos. De maneira simultânea e, progressivamente, em maior intensidade, também ocorre um declínio na taxa de síntese protéica corpórea. Além de menor síntese, que ocorre no fígado, este órgão também diminui sua taxa de liberação para periferia de proteína sintetizada, como por exemplo a albumina. Essas alterações resultam em um padrão protéico, orgânico, alterado, com grave comprometimento da proteína muscular. De uma maneira evolutiva - uma menor ingestão protéica/aminoacídica-ocorrem alterações de níveis hormonais e/ou metabólicas. A seguir, serão discutidos aspectos selecionados e relacionados à ingestão protéica da dieta, balanço nitrogenado, níveis de aminoácidos plasmáticos, proteínas séricas, estudos cinéticos, relacionados ao metabolismo protéico, e sua avaliação clínica.

\section{DETERMINAÇÃO DO CON- TEÚDO PROTÉICO DA DIETA}

O método mais freqüente de avaliar a quantidade de proteína da dieta tem sido a determinação do seu conteúdo em nitrogênio total e sua multiplicação por 6,25. Isso se deve ao fato de que aproximadamente $16 \%$ da proteína é constituída de nitrogênio ${ }^{(1,7,8)}$. No entanto, pelo menos, dois fatores de erro têm que ser considerados, ou seja, nem todo o nitrogênio dos alimentos ingeridos é protéico, e a proporção nitrogênio/proteína dos diferentes alimentos é variável. A Tabela I lista alguns fatores de conversão nitrogênio/proteína.

\begin{tabular}{lr}
$\begin{array}{l}\text { Tabela I - Alguns fatores de conversão do nitro- } \\
\text { gênio em proteína* }\end{array}$ \\
\hline Alimento & Fator \\
\hline Macarrão, espaguete & 5,70 \\
Arroz, várias apresentações & 5,95 \\
Soja, várias apresentações & 5,91 \\
Sementes, como girassol & 5,30 \\
Leites e derivados & 6,38
\end{tabular}

* Modificado de World Health Organization Technical Report Series ${ }^{(9)}$.

A presença de nitrogênio não protéico, nos alimentos, é significativamente maior nos alimentos de origem vegetal. Esse grupo de substâncias inclui uréia, creatinina, ácidos nucléicos, no caso de proteínas de origem animal, e, no caso de vegetais, uma série de aminoácidos não utilizáveis pelo homem. Estima-se que 1 a $2 \%$ do nitrogênio de origem animal seja não 
protéico e que $1 / 3$ deste esteja sob a forma de aminoácidos livres. No entanto, essa proporção pode variar, como em certos peixes nos quais, 9 a $18 \%$ do nitrogênio é não protéico. No leite humano, $20 \%$ e, no de vaca, $5 \%$ é não protéico. Quando o nitrogênio não protéico se apresenta sob forma de aminoácidos livres, não ocorre alteração da qualidade protéica do alimento $^{(1)}$. O problema maior ocorre nas fontes protéicas de origem vegetal. Enquanto que 95\% do nitrogênio de sementes é proteína, nas folhas, a proporção chega a $80-90 \%$, nos caules e raízes pode atingir $60 \%$ e, nas partes vegetais de reserva, como na batata e na cenoura, o nitrogênio protéico corresponde a $\pm 30 \%$ do total. A maior parte desse nitrogênio vegetal, não protéico é de aminoácidos, e os mais freqüentes são a glutamina, asparagina, arginina e lisina, sendo reduzido o teor de aminoácidos essenciais e aumentada a quantidade de aminoácidos que não participam do metabolismo protéico humano, como o ácido $\gamma$-aminobutírico, a $\beta$-alanina e o ácido $\alpha$-amino adípico. Muitos desses aminoácidos são excretados, inalterados, na urina. A proporção nitrogênio/proteína, em geral, varia entre $15,7 \%$, no caso do leite, até $19 \%$, no caso de castanhas. Por esse motivo, o fator de conversão de nitrogênio para proteína é, por exemplo, de 6,38 para leites e derivados, 5,70 para cereais e 5,55 para gelatina. A farinha de mandioca tem $0,32 \%$ de nitrogênio, o que seria equivalente a $2 \%$ de proteína, quando se utiliza o fator 6,25 , mas contém $\pm 42 \%$ de nitro- gênio não protéico, sendo 2/3 amônia. Esses cálculos, em relação à mandioca, claramente demonstram como a proteína desse alimento é superestimada ${ }^{(1)}$.

Uma das maneiras propostas para se calcular a ingestão protéica correta é considerar o valor biológico e a composição de aminoácidos da dieta, incluindo todos os alimentos presentes em uma determinada refeição ${ }^{(11,12,13)}$. Assim, também, não é recomendado o cálculo genérico de uma oferta protéica, baseado no valor nutritivo de cada um dos alimentos de maneira independente. Estudos com a mistura de arroz e feijão, mostram que, na proporção protéica de 1:1, atinge-se o equilíbrio nitrogenado, em jovens eutróficos, quando a oferta é de $\pm 0,64 \mathrm{~g} / \mathrm{kg} / \mathrm{dia}^{(14,15)}$. No entanto, o mesmo pode não ser verdade se existirem outras fontes vegetais protéicas na refeição e/ou a proporção entre leguminosas e cereais não for a mais adequada. A Tabela II apresenta valores de digestibilidade e cômputo de aminoácidos em diferentes alimentos. Estudos biológicos em ratos mostram o alto valor protéico dessa mistura de arroz e feijão, embora isoladamente o arroz seja deficiente em lisina e o feijão em metionina $^{(16,17)}$.

Um outro tipo de proteína vegetal é a soja ${ }^{(18 / 21)}$. Individualmente, é dos produtos vegetais, das leguminosas, de maior conteúdo protéico ${ }^{(12,13)}, 30$ a $40 \%$. Experimentos mostram que o balanço nitrogenado de indivíduos, recebendo dieta com arroz e soja, atinge o equilíbrio com oferta protéica inferior a $0,65 \mathrm{~g} / \mathrm{kg} / \mathrm{dia}^{(22)}$.

Tabela II - Valores de digestibilidade e cômputo químico para alguns alimentos

\begin{tabular}{lccc}
\hline & Digestibilidade (\%) & Cômputo químico (\%) e aminoácido limitante \\
\hline Arroz polido & 84 & 72 & lisina \\
Batata & 65 & 63 & metionina + cistina \\
Carne bovina & 97 & 100 & \\
Peixe & 97 & 99 & triptofano \\
Caseína & 98 & 99 & metionina + cistina \\
Farinha de trigo & 40 & 41 & lisina \\
Maçã & 85 & 60 & metionina + cistina \\
Banana & 85 & 51 & leucina \\
Laranja & 85 & 27 & leucina \\
Gelatina & 97 & 1 & triptofano \\
Glúten de trigo & 96 & 35 & lisina \\
Leites e derivados & 97 & 77 & valina \\
Macarrão, espaguete & 86 & 59 & lisina \\
Milho & 90 & 52 & lisina \\
Ovos & 97 & 100 & \\
Raízes & 74 & 50 & metionina + cisitina \\
Soja & 78 & 97 & metionina + cistina \\
\hline
\end{tabular}

* Modificado das referências 7, 8, 9 . 


\section{BALANÇO NITROGENADO}

O balanço nitrogenado é definido como a diferença entre a quantidade ingerida e perdida pelo organismo (Tabela III). Como nitrogênio ingerido, considera-se o da dieta e o reabsorvido de secreções digestivas e de vias urinárias. No cômputo do nitrogênio perdido, considera-se a soma do urinário, fecal e de perdas obrigatórias como pele, pêlo, secreções, unha. Depreende-se que os dois principais erros do balanço nitrogenado são a estimação do nitrogênio ingerido e a do nitrogênio perdido ${ }^{(3)}$. Em geral, os erros são cumulativos, pois há, freqüentemente, uma superestimação do nitrogênio ingerido e subestimação do nitrogênio perdido. Diversos estudos têm sido realizados, como, por exemplo em crianças subnutridas, com marasmo e "kwashiokor" (23), pacientes desnutridos ${ }^{(24)}$, crianças $^{(25)}$, alocoólatras ${ }^{(26 / 29)}$, idosos ${ }^{(30)}$ e em indivíduos eutróficos ${ }^{(31)}$, através do balanço nitrogenado. nada aumentada, tornando o balanço nitrogenado intensamente negativo. A oferta nitrogenada pode vir a tornar o balanço equilibrado e, por vezes, positivo. Tal oferta tem por objetivo não só garantir a oferta das necessidades protéicas basais do paciente, como também nitrogênio suficiente para reposição das perdas. Se o problema do paciente estiver relacionado principalmente ao jejum forçado, pela utilização somente de soros glicosados e fisiológicos, haverá benefício nítido com a introdução de soluções protéicas. Por outro lado, a oferta nutricional, por mais que pareça estar nutricionalmente correta, por si só não vai ser suficiente para a cura do paciente. Sempre é necessário cuidar da causa básica, seja ela infecciosa, traumática ou inflamatória. Existem evidências de que, nessa situação, a oferta de $1,5 \mathrm{~g}$ de proteína $/ \mathrm{kg} /$ dia aumenta tanto a síntese protéica como a degradação, sem benefício ao balanço nitrogenado do paciente ${ }^{(32 / 35)}$.

\section{RNA, DNA E ENZIMAS TISSULARES}

O impacto da nutrição sobre o teor de componentes celulares varia conforme o estado nutricional, particularmente no fígado, onde ocorrem as maiores alterações. Assim, por exemplo, a ingestão protéica, aumentada causa, no fígado, um aumento significativo da relação proteína intracelular/DNA total. Fato semelhante, porém em menor escala, ocorre no músculo. Por outro lado, a relação citada é constante no sistema nervoso e rim. As maiores transformações, ocorridas no fígado, se devem ao fato de ser ele um
Nas situações onde ocorre carência protéica, há, também, redução intracelular do teor de aminoácidos livres, tanto essenciais como não essenciais, e diminuição da excreção urinária de nitrogênio, resultando menor perda orgânica de proteína (Figura 2). Nessa situação clínica, uma menor quantidade de nitrogênio (proteína) ingerida é necessária para recuperar o equilíbrio nitrogenado, mas, quando a oferta protéica é maior, o balanço de nitrogênio se positiva mais rapidamente. Essa maior positividade do balanço nitrogenado pode ser explicada pela recuperação mais rápida do teor de aminoácidos livres, principalmente no fíga$\mathrm{do}^{(2)}$. Pacientes críticos, portadores de lesão orgânica extensa e, muitas vezes, atingindo mais de um órgão alvo, apresentam perda nitroge-

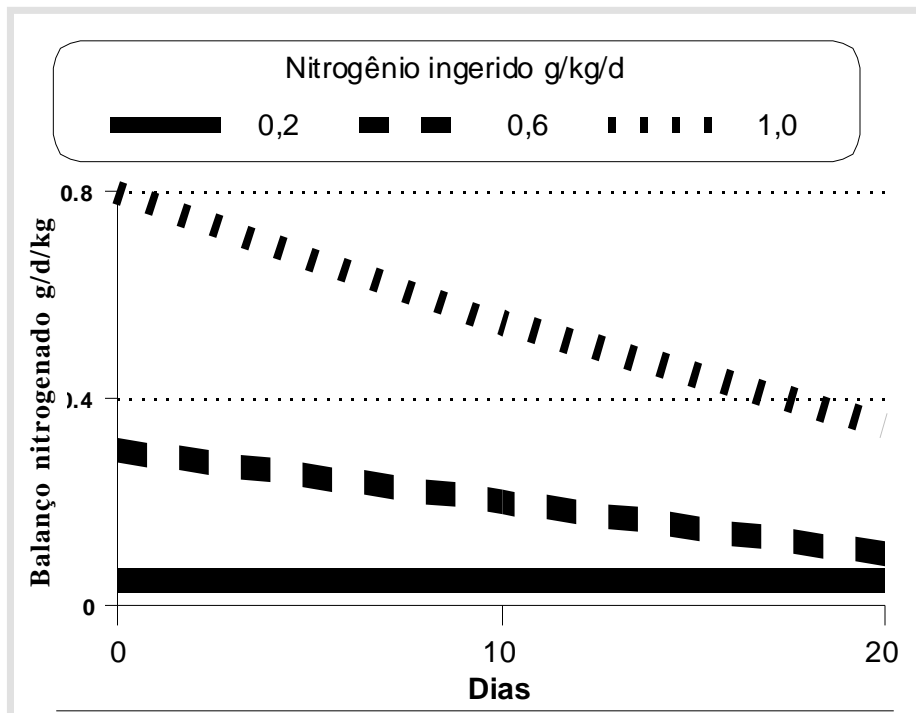

Figura 2 - Balanço nitrogenado em cães desnutridos, recebendo diferentes quantidades de proteínas ${ }^{(36)}$ 
órgão onde ocorre intensa síntese protéica e possui concentração intracelular de aminoácidos livres maior e mais disponível que a de outros tecidos orgânicos. Assim sendo, o impacto de alterações, na oferta de proteína, é maior no fígado, pois não ocorre alteração da quantidade total de DNA. A elevação do teor de aminoácidos livres, ou protéica, hepática e intracelular, ocorre de maneira paralela à da quantidade total de RNA, sem alterar a do DNA. Já em situações de carência protéica, ocorre uma queda imediata da síntese e da degradação protéica muscular. Ao que parece, devido a alteração na eficiência do processo de translação (mRNA) medida pela taxa de síntese protéica por unidade de RNA celular, as alterações são progressivas. Já no fígado, no mesmo período em que ocorrem as transformações no músculo, há manutenção e inclusive aumento compensatório da taxa de reciclagem protéica ${ }^{(1,37,38,39)}$.

\section{PROTEÍNAS SÉRICAS}

A concentração de diferentes proteínas séricas específicas tem sido utilizada para avaliar o metabolismo protéico, orgânico. As diferentes proteínas séricas se recuperam de maneira diferente, dependendo dos diferentes tecidos e compartimentos do organismo. Por exemplo, a albumina sérica diminui rapidamente, quando se oferece alimentação baixa em proteína, porém tal fato não ocorre com as globulinas. $\mathrm{Na}$ presença de subnutrição, as proteínas intestinais e hepáticas são as que mais sofrem. De maneira similar, demonstra-se que as proteínas do tecido cerebral não diminuem tão drasticamente ${ }^{(4,40,41,42)}$. A Tabela IV apresenta as proteínas séricas usualmente utilizadas para a avaliação protéica. A principal limitação do uso das mesmas relaciona-se ao fato de que podem ser afetadas por várias patologias, como as hepáticas, infecciosas e aquelas secundárias à ingestão anormal de nutrientes (proteína, tiamina, ferro, vitamina $\mathrm{A}$, etc). Níveis séricos de albumina não parecem se relacionar à deficiência aguda protéica, mas níveis baixos são indicadores de maior morbidade e mortalidade. As proteínas de meia vida muito curta parecem ter uma correlação positiva com a medida de eficácia do suporte nutricional. Também, pode-se sugerir que outras proteínas, relacionadas à resposta de fase aguda ao trauma, poderiam ser indicadoras da eficácia nutricional e suporte nutricional adequado.

\section{AMINOÁCIDOS PLASMÁTICOS}

Os níveis de aminoácidos plasmáticos, freqüentemente, apresentam elevação após a ingestão de dieta protéica ${ }^{(1,2,6)}$. Determinação simultânea dos níveis de aminoácidos, nas veias radial e portal, mostram que as concentrações são superiores na veia porta e que, muitas vezes, o aumento não ocorre na veia radial (Figura 3). Pacientes portadores de desnutrição, principalmente protéica, apresentam, em geral, níveis de aminoácidos plasmáticos que se caracterizam por: 1) queda dos níveis de todos os aminoácidos;2) entre os aminoácidos essenciais ocorre queda mais acentuada dos aminoácidos ramificados, leucina, isoleucina e valina; a fenilalanina e a lisina são os mais poupados; 3) entre os aminoácidos não essenciais, a queda maior é de tirosina; 4) os aminoácidos não essenciais, glicina, alanina, prolina, histidina, serina e ácido aspártico, têm seus níveis plasmáticos mantidos e, algumas vezes, até aumentado; 5) essas alterações seriam proporcionais à gravidade do quadro clínico. O jejum tem sido caracterizado por elevação dos níveis de leucina, isoleucina e valina e, em menor escala, da metionina, com queda dos outros aminoácidos essenciais. Após a infusão de glicose, tem sido observada queda acentuada de todos os aminoácidos. Em contraste às alterações aminoacídicas observadas nos casos de "kwashiorkor", elas não são freqüentes e/ou específicas em casos de marasmo. A Tabela V apresenta valores médios de aminoácidos plasmáticos e urinários.
Tabela IV - Proteínas séricas comumente utilizadas para avaliar o estado protéico $^{(4,5,42)}$

\begin{tabular}{lcl}
\hline & Meia vida - dias & \multicolumn{1}{c}{ Uso clínico } \\
\hline Albumina & 18 & Má nutrição grave \\
Transferrina & $8-9$ & Má nutrição \\
Pré-albumina & 2 & Depleção aguda \\
Proteína ligadora do retinol & 0,5 & Depleção aguda \\
Fibronectina & $0,25-1$ & Finalidade de monitorizar \\
Perfil de aminoácidos & - & Prognóstico \\
\hline
\end{tabular}




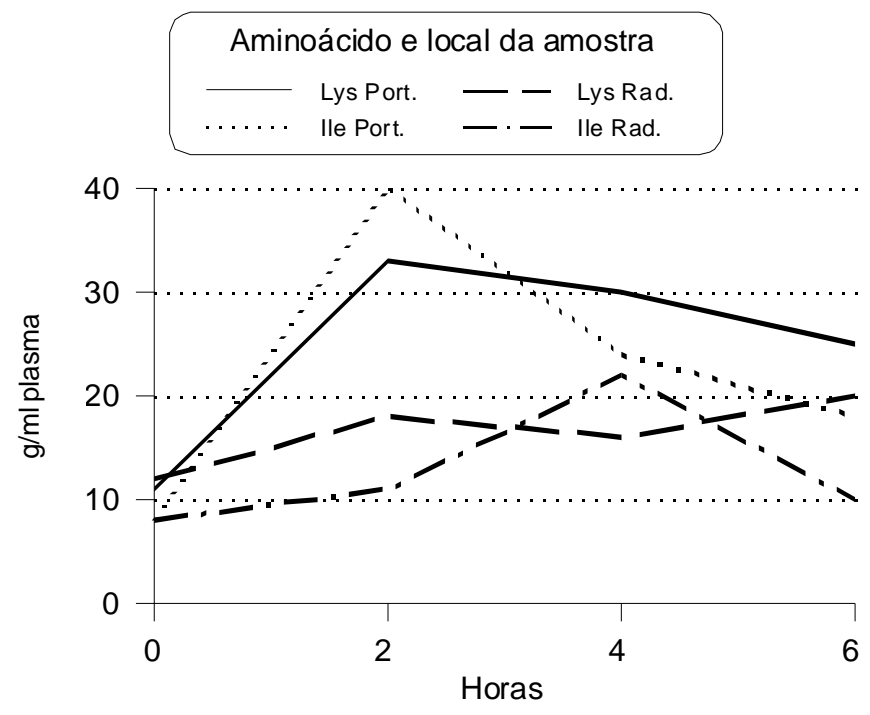

Figura 3 - Níveis plasmáticos de lisina (lys) e isoleucina (Ile) nas veias porta (Port.) e radial (Rad.), após refeição protéica (43)

\section{MEDIDAS URINÁRIAS}

Em vista da sensibilidade das proteínas musculares a alterações do metabolismo protéico, e de a massa muscular corresponder a aproximadamente $42 \%$ da corpórea e de que a conversão de creatina em creatinina ocorre espontaneamente e predominantemente $( \pm 95 \%)$ no músculo, o índice creatinina/altura tem sido advogado como parâmetro para avaliar a massa protéica do indivíduo ${ }^{(5)}$. Considerando que a massa de creatina muscular está diretamente relacionada à utilização energética do músculo e que esta é proporcional à massa muscular total, a excreção urinária de creatinina também é proporcional a esta massa muscular. Assim sendo, nos processos carenciais, quando ocorre diminuição da massa muscular, também ocorre menor gasto energético pelo músculo, e conseqüentemente, menor produção de creatinina

Tabela V - Níves de aminoácidos plasmáticos, após 8 horas de jejum, e urinários, $\mu \mathrm{mol} / L^{*}$

\begin{tabular}{|c|c|c|c|c|c|c|c|c|}
\hline $\begin{array}{c}\text { Aminoácido } \\
\text { peso molecular }\end{array}$ & $\begin{array}{l}\text { Recém-nas- } \\
\text { cido }\end{array}$ & $\begin{array}{c}\text { Criança } \\
2 \text { anos (46) }\end{array}$ & Adulto & $\begin{array}{l}\text { Alcoólatras }(\square) \\
\text { média }{ }^{(47)}\end{array}$ & $\begin{array}{c}\text { Idosos } \\
>60 \text { anos } \\
\end{array}$ & Adulto & $\begin{array}{l}\text { Músculo } \\
\text { livre(§) }\end{array}$ & $\begin{array}{c}\text { Músculo } \\
\text { proteína(§) }\end{array}$ \\
\hline Alanina- 89,09 & $21-37$ & $99-313$ & $213-472$ & 822(‡) & 312 & 316 & 96 & 66225 \\
\hline Arginina - 174,20 & $4-15$ & $11-65$ & $40-140$ & 89(‡) & 65 & 86 & 46 & 21240 \\
\hline Ác.aspártico - 133,10 & traço-2 & traço-9 & $1-11$ & 53 & 19 & - & - & - \\
\hline Cistina - 121,16 & $8-20$ & traço-40 & $70-108$ & 27 & 117 & - & - & - \\
\hline Fenilalanina - 165,19 & $7-18$ & $23-69$ & $38-73$ & 74 & 66 & 53 & 62 & 32690 \\
\hline Glicina - 75,07 & $17-39$ & $56-308$ & $179-587$ & 554 & 224 & 248 & 1304 & 41295 \\
\hline Glutamina - 146,15 & $79-140$ & $46-290$ & $140-570$ & 189 & - & 655 & 20050 & - \\
\hline Histidina - 155,16 & $8-18$ & 24-112 & $32-97$ & 77 & 88 & 87 & 592 & 17401 \\
\hline Isoleucina - 131,18 & $4-7$ & $26-94$ & $40-99$ & 71 & 67 & 63 & 68 & 41927 \\
\hline Leucina - 131,18 & $6-14$ & $45-155$ & $78-176$ & 166 & 120 & 120 & 133 & 59460 \\
\hline Lisina - 146,19 & $17-39$ & $45-144$ & $105-207$ & 187 & 210 & 195 & 994 & 54723 \\
\hline Metionina - 149,21 & $1-6$ & $3-29$ & $11-30$ & 291 & 22 & 25 & - & 31499 \\
\hline Prolina - 115,13 & $12-32$ & $51-185$ & $103-290$ & 303 & 195 & - & - & - \\
\hline Serina - 105,09 & $10-26$ & 24-172 & $76-164$ & 248 & 208 & 114 & 584 & 44724 \\
\hline Taurina - 125,15 & $9-27$ & $19-91$ & $32-138$ & 227 & - & 49 & 19200 & - \\
\hline Tirosina - 181,19 & $8-18$ & $11-122$ & $22-83$ & 81 & 64 & 60 & 82 & 35322 \\
\hline Treonina - 119,12 & $14-40$ & $33-128$ & $76-194$ & 176 & 126 & 128 & 571 & - \\
\hline Triptofano - 204,23 & traço-14 & - & - & $37 \ddagger$ & 29 & 43 & - & - \\
\hline Valina - 117,15 & $9-29$ & $57-262$ & $168-317$ & 270 & 202 & 220 & 253 & 43534 \\
\hline
\end{tabular}

(*) $\quad \mu \mathrm{mol} / \mathrm{L}=(\mathrm{mg} / \mathrm{L} \times 1000) /($ Peso molecular $) ; \mathrm{mg} / \mathrm{L}=(\mathrm{mmol} / \mathrm{L} \times$ Peso molecular $) / 1000$

(प) Pacientes alcoólatras, crônicos, há pelo menos trinta dias de abstnência, recebendo suporte nutricional enteral.

(¥) $p<0.065$ em relação ao valor de internação.

(§) Músculo livre = Teor de aminoácidos livres na células musculares, $\mu \mathrm{mol} / \mathrm{L}$ água intracelular. Músculo proteína = Teor de aminoácidos na proteína humana muscular, $\mu \mathrm{mol}$ AA/100 g proteína.

(I) Dados pessoais. 
a partir de creatina, com menor excreção urinária de creatinina. Comumente, o índice creatinina/altura, ICA, é utilizado para avaliar a massa corpórea protéica (muscular), ou seja:

$$
\text { Índice creatinina/altura }=\frac{\text { Excreção urinária de creatinina } 24 h \times 100}{\text { Excreção urinária ideal de creatinina }}
$$

Excreção urinária ideal de creatinina

$$
\begin{aligned}
& \sigma^{\prime \prime}=23 \mathrm{mg} \text { X PESO kg} \\
& \bigcirc=18 \mathrm{mg} X \text { PESO } \mathrm{kg}
\end{aligned}
$$

Valores de ICA entre 60 e $80 \%$ são associados à desnutrição protéica, moderada, e valores inferiores a 40\%, à grave. Para que a interpretação desse índice seja correta, é necessário que a coleta da urina seja acurada e se evite o crescimento anormal, bacteriano, durante a coleta.

\section{ESTUDOS DA SÍNTESE PROTÉICA COM MAR- CADORES NÃO RADIOATIVOS}

Os isótopos estáveis do carbono, oxigênio, hidrogênio e nitrogênio podem ser utilizados como parte de aminoácidos específicos, utilizados para avaliação dos processos de síntese (Figura 4) e degradação protéicas ${ }^{(31,44,45)}$. Esses isótopos são naturalmente distribuídos na natureza, o que os torna inócuos aos seres biológicos em geral. Dois modelos gerais de estudo do metabolismo protéico são utilizados com o uso de isótopos estáveis. Um deles emprega uma dose única do traçador e, no outro, é feita uma infusão contínua, até que o estado de equilíbrio metabólico seja atingido ${ }^{(1,46)}$.

Os estudos que utilizam dose única do traçador, em geral, utilizam uma dose, por exemplo, ${ }^{15} \mathrm{~N}$-glicina, via oral, e conseqüiente determinação do enriquecimento urinário de ${ }^{15} \mathrm{~N}$-uréia e ${ }^{15} \mathrm{~N}$-amônia. A Tabela VI mostra os resultados cinéticos, em indivíduos jo- vens, eutróficos, submetidos à dieta isoprotéica, com oferta baixa $(-30 \%)$ ou alta $(+30 \%)$ de energia. Os resultados sugerem que as pessoas jovens, eutróficas, recebendo dieta de arroz e feijão, com baixa caloria, são capazes de manter balanço protéico, cinético, apesar do menor balanço nitrogenado e uma excreção aumentada de uréia e amônia ${ }^{(47)}$.

O outro exemplo de estudo cinético, relacionado ao metabolismo protéico, é feito pela infusão contínua de aminoácido marcado. Como exemplo, foi estudado o efeito da adição e da quantidade ingerida de nitrogênio não essencial na alimentação (isocalórica e com mesma quantidade de aminoácidos essenciais) sobre a oxidação de leucina e a hidroxilação de fenilalanina. A oferta de nitrogênio, na forma de aminoácido não essencial ou inespecífico, variou em qualidade, ora somente aminoácidos não essenciais, sem glutamina, ora mais glutamina, e, por fim, somente glutamina. Os resultados mostraram que, em indivíduos jovens, eutróficos, não existe efeito detectável do nitrogênio inespecífico sobre a oxidação de leucina, ou sobre a hidroxilação de fenilalanina, ou, ainda, sobre a taxa de reciclagem protéica, medida pela incorporação protéica de $1-{ }^{13} \mathrm{C}$-leucina ou ${ }^{2} \mathrm{H}_{5}$-anel-fenilalanina ${ }^{(48)}$.

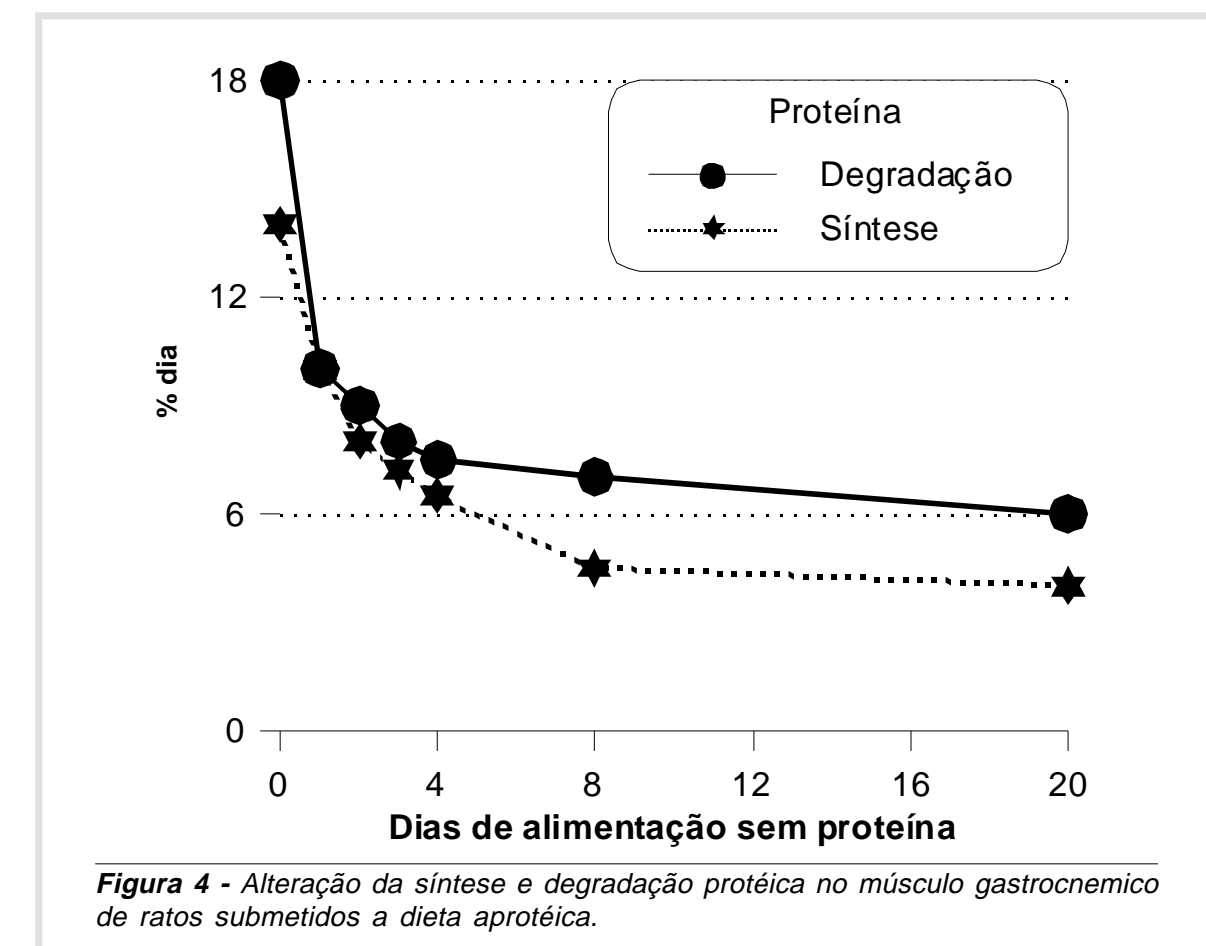


Tabela VI - Estudo de balanço protéico, cinético, com duração de nove horas, em jovens eutróficos, recebendo arroz e feijão, isonitrogenada, com baixa $(-30 \%)$ ou alta $(+30 \%)$ oferta energética ${ }^{(47)}$

\begin{tabular}{|c|c|c|c|c|c|}
\hline \multirow[b]{3}{*}{ Ingestão nitrogênio mg/kg/9h } & \multicolumn{4}{|c|}{ Ingestão energética } & \multirow{3}{*}{$\frac{\text { valor do } p}{0.7753}$} \\
\hline & Baixa & \multicolumn{3}{|c|}{ Alta } & \\
\hline & $73 \pm 8$ & 72 & \pm & 10 & \\
\hline Ingestão calórica $\mathrm{kcal} / \mathrm{kg} / 9 \mathrm{~h}$ & $14 \pm 1$ & 22 & \pm & 2 & 0.0002 \\
\hline Nitrogênio uréico urinário - mg/9h & $4471 \pm 596$ & 3629 & \pm & 1007 & 0.2160 \\
\hline${ }^{15}$ Nitrogênio uréico urinário - mg/9h & $4,8 \pm 0,9$ & 3,7 & \pm & 1,3 & 0.1333 \\
\hline Amônia urinária - mg Nitrogênio/9h & $369 \pm 126$ & 309 & \pm & 124 & 0.1050 \\
\hline Amônia urinária - mg ${ }^{15}$ Nitrogênio/9h & $1,5 \pm 1,0$ & 1,4 & \pm & 0,6 & 0.8085 \\
\hline Fluxo de nitrogênio ou taxa total de reciclagem - g N/9h & $21 \pm 6$ & 18 & \pm & 4 & 0.4717 \\
\hline Síntese protéica - g/1000kcal/9h & $118 \pm 48$ & 64 & \pm & 18 & 0.0761 \\
\hline Degradação protéica - g/1000kcal/9h & $101 \pm 41$ & 81 & \pm & 26 & 0.4945 \\
\hline Balanço nitrogenado - $\mathrm{mg} / \mathrm{kg} / \mathrm{d}$ & $2 \pm 22$ & 24 & \pm & 16 & 0.0077 \\
\hline
\end{tabular}

MARCHINI JS et al. Protein metabolism investigation: clinical and experimental aspects. Medicina, Ribeirão Preto, 31: 22-30, jan./march 1998.

ABSTRACT: The clinical protein metabolism investigation is related to evaluation that ranges from a diet protein intake to muscle protein synthesis. This review paper intent to summarize the following protein metabolism aspects: protein intake; amino acid diet composition; nitrogen urine excretion and nitrogen balance; plasma levels of amino acids and proteins and whole body protein synthesis. The method may change according to specific objective. The nutritional patient evaluation, his protein intake, as well as protein nutritional support, plays a pivotal role on the patient recovery.

UNITERMS: Proteins. Metabolism. Amino Acids. Nutrition.

\section{REFERÊNCIAS BIBLIOGRÁFICAS}

1 - MUNRO HN \& ALLISON JB, eds. Mammalian protein metabolism. Academic Press, New York, 1964.

2 - YOUNG VR \& MARCHINI JS. Mechanisms and nutritional significance of metabolic response to altered intakes of protein and amino acids, with reference to nutritional adaptation in humans. Am J Clin Nutr 51: 270-289, 1990.

3 - YOUNG VR; MARCHINI JS \& CORTIELLA J. Assessment of protein nutritional status. J Nutr 120: 1496-1502, 1990.

4 - MARCHINI JS et al. Avaliação nutricional do paciente hospitalizado. Universidade (Cuiabá) 4: 21-29, 1984.

5 - VANNUCCHI H et al. Avaliação antropométrica e bioquímica do estado nutricional. Medicina (Ribeirão Preto) 17: 17-28, 1984

6 - DUTRA DE OLIVEIRA JE \& MARCHINI JS. Clinical and subclinical nutritional deficiencies. Int J Vitamin Nutr Res 26: 59-65, 1984.

7 - HENRY KM; CARMACK RM \& KOSTERLITZ HW. The determination of the nutritive value of a protein by its effects on liver nitrogen in rats. Br J Nutr 15: 199-205, 1961.
8 - MITCHELL HH; HAMILTON TS \& BEADLES JR. The nutritional effects of heat on food protein, with particular reference to commercial processing and home cooking. J Nutr 39: 418-429, 1949.

9 - JOINT FAO/WHO. Energy and protein requirements, report of a joint FAO/WHO "ad hoc" expert committe. WHO Tech Rep Ser 522: p. 1-130, 1973.

10 - ADDIS T; POO LJ \& LEW W. Protein loss from liver during a two day fast. J Biol Chem 115: 117-118, 1936.

11 - MARCHINI JS et al. Cálculo das recomendações de ingestão protéica: aplicação a pré-escolares, escolar e adulto utilizando alimentos brasileiros. Rev Saúde Pública São Paulo 28: 146-152, 1994.

12 - SOUZA N \& DUTRA DE OLIVEIRA JE. Estudo experimental sobre o valor nutritivo do arroz e feijão. Braz J Med Biol Res 2: 175-180, 1969.

13 - SOUZA N \& DUTRA DE OLIVEIRA JE. Self selection on dietary protein from rice and beans. Ecol Food Nutr 3: 3-5, 1974. 
14 - VANNUCCHI H; DUARTE RMF \& DUTRA DE OLIVEIRA JE. Nutritive value of a rice and bean based diet for agricultural migrant workers in Southern Brazil. Nutr Report Intern 24: 129-134, 1981.

15 - VANNUCCHI H; DUARTE RMF \&, DUTRA DE OLIVEIRA JE. Studies on the protein requirements of Brazilian rural workers ("Boias-Frias") given a rice and bean diet. Int $\mathbf{J}$ Vitamin Nutr Res 53: 338-344, 1983.

16 - DUTRA DE OLIVEIRA JE. Valor nutritivo de proteínas alimentares. Estudo metabólico realizado em crianças desnutridas. Tese de Livre Docência, Faculdade de Medicina de Ribeirão Preto da USP, Ribeirão Preto, p. 1-105, 1962.

17 - DUTRA DE OLIVEIRA JE; SCATENA L \& DUARTE GG. Metabolic studies on the supplementary value of animal and vegetal protein. Nutr Diet 9: 249-258, 1967.

18 - MARCHINI JS \& DUTRA DE OLIVEIRA JE. Alguns aspectos nutricionais e sociais dos "Bóias-Frias". An Sem Serv Soc (Franca, SP) 2: 21-26, 1983.

19 - MARCHINI JS \& DUTRA DE OLIVEIRA JE. Valor nutritivo de um isolado protéico de soja disponível no Brasil. In: Anais, III Seminário Nacional de Pesquisa de Soja, Campinas-SP, p. 912-920, 1984.

20 - MARCHINI JS; FREITAS O \& DUTRA DE OLIVEIRA JE. Avaliação bioquímica e nutricional de dois hidrolisados enzimáticos de proteína de soja. Cienc Tecnol Alim 5: 12-21, 1985.

21 - DUTRA DE OLIVEIRA JE \& SCATENAL. Nutritional value of the protein from a soybean milk powder. J Food Sci 32: 592-594, 1967

22 - VEIGA EV et al. The nutritive value of a rice and soybean diet for adults. Nutr Res 5: 577-583, 1985.

23 - DUTRA DE OLIVEIRA JE; SCATENA L \& OLIVEIRA NETO N. Clinical picture and nitrogen retention in malnourished children. Am J Clin Nutr 19: 352-356, 1966.

24 - MARCHINI JS et al. Nutrição enteral quimicamente definida em pacientes do Hospital das Clínicas de Ribeirão Preto. Rev Paul Med 97: 148-152, 1981.

25 - SANTOS JE et al. Relationship between the nutritional efficacy of a rice and bean diet and energy intake in preschool children. Am J Clin Nutr 32: 1541-1544, 1979.

26 - MARCHINI JS. Estudo sobre as necessidades protéicas de alcoólatras crônicos. Tese de Doutorado, Faculdade de Medicina de Ribeirão Preto da USP, Ribeirão Preto, $\mathrm{p} 1-95,1983$.

27 - MARCHINI JS \& DUTRA DE OLIVEIRA JE. Endogenous nitrogen excretion in alcoholic patients on an enteral diet. Braz $\mathbf{J}$ Med Biol Res 23: 489-498, 1990.

28 - MARCHINI JS; VANNUCCHI H \& DUTRA DE OLIVEIRA JE. Protein requirements of a group of chronic alcoholics: efficiency of duodenal amino acid infusion. Nutr Res 8: 239-248, 1988.

29 - MARCHINI JS; VANNUCCHI H \& DUTRADE OLIVEIRA JE. Effect of two carbohydrate:lipid ratios of diets enterally fed to chronic alcoholics. Hum Nutr Clin Nutr 37: 329-338, 1983.

30 - UNAMUNO MRDL et al. Protein requirement assessment of elderly men on rice and beans diet. Nutr Res 11:149-157, 1991.

31 - MARCHINI JS et al. Requirements for indispensable amino acids in adult humans: longer-term amino acid kinetic study with support for the adquacy of the Massachusetts Institute of Technology amino acid requirement pattern. Am $\mathbf{J}$ Clin Nutr 58: 670-683, 1993.
32 - SANTOS JE et al. Suporte nutricional, enteral $x$ parenteral. Bol Soc Bras Nutr Parent 3: 9-10, 1980.

33 - MARCHINI JS \& VANNUCCHI H. Nutrição enteral com fórmulas quimicamente definidas. Alguns aspectos práticos. Medicina, (Ribeirão Preto) 17: 171-180, 1984

34 - VANNUCCHI H et al. Dez anos de experiência em nutrição enteral monomérica. Medicina, (Ribeirão Preto) 24: 165-174, 1991.

35 - SHAW JHF; WILDBORE M \& WOLFE RR. Whole body proteinkinetics in severely septic patients. Ann Surg 205: 288-294, 1987.

36 - ALLISON HL \& BIRD JWC. Elimination of nitrogen from the body. In: MUNRO HN \& ALLISON JB. eds. Mammalian protein metabolism. Academic Press, New York, 1964, p. $483-493$.

37 - WAINIO WW et al. Oxidative enzymes of the liver in protein depletion. J Nutr 49: 465-473, 1953.

38 - WAINIO WW et al. Enzymes in protein depletion. III. Enzymes of brain, kidney, skeletal muscle and spleen. J Nutr 67: 197-204, 1959

39 - WAINIO WW et al. Enzymes in protein depletion. II. Oxidative enzymes of heart ventricule. J Nutr 52: 565-573, 1954

40 - ADDISON E et al. Estudo nutricional de pacientes hospitalizados. Subsídios a favor da criação de comissões de suporte nutricional. Rev Soc Bras Nutr Parent 3 (6): 9-12, 1986.

41 - DUTRA DE OLIVEIRA JE; MARCHINI JS \& DEMONTE A. Proteínas. In: CARAZZA F \& MARCONDES E, eds. Nutrição clínica em pediatria. Sarvier Editora, São Paulo, p 85-100, 1991.

42 - MARCHINI JS; ANSELMO MAC \& BURINI RC. Avaliação nutricional de pacientes hospitalizados. Rev Soc Bras Nutr Parent 3 (7): 25-29, 1986.

43 - RENNIE MJ. Protein and amino acid metabolism in the whole body and in the tissues. In: PAYNE-JAMES J; GRIMBLE G \& SILK D, eds. Artificial nutrition support in clinical practice. Edward Arnold, London, p. 13-41, 1995.

44 - CORTIELLA J et al. Phenylalanine and tyrosine kinetics in relation to altered protein and phenylalanine and tyrosine intakes in healthy young men. Am J Clin Nutr 56: 517-525, 1992.

45 - MARCHINI JS et al. Liver and kidney nitrogen uptake in rats fed beans enriched with ${ }^{15}$ Nitrogen through $\left({ }^{15} \mathrm{NH}_{4}\right)_{2} \mathrm{SO}_{4}$ used as soil fertilizer. Braz J Med Biol Res 23: 667-669, 1990.

46 - WATERLOW JC; GARLICK PJ \& MILLWARD DJ. Protein turnover in mammalian tissues and in the whole body. North-Holland Publishing, Amsterdam, 1978, 804 p.

47 - MARCHINI JS et al. Whole-body protein metabolism turnover in men on a high or low calorie rice and bean Brazilian diet. Nutr Res 16: 435-441, 1996.

48 - HIRAMATSU T et al. Source and amount of dietary nonspecific nitrogen in relation to whole-body leucine, phenylalanine, and tyrosine kinetics in young men. Am J Clin Nutr 59: 1347-1355, 1994.

49 - DIEM K \& LENTNER C. Documenta Geigy. Tablas científicas. Ciba-Geigy, Basile, Switzerland, 1975, 819 p.

50 - VANNUCCHI H et al. Plasma amino acid patterns in alcoholic pellagra patients. Alcohol Alcohol 26: 431-436, 1991.

Recebido para publicação em 30/01/98

Aprovado para publicação em 25/02/98 